\title{
The brain craving for gambling? Neurosciences and addiction concept in clinical practice
}

\author{
Ilpo Helén ${ }^{1}$ and Joonas Toivio ${ }^{2}$ \\ ${ }^{1}$ Department of Social Sciences, University of Eastern Finland, Joensuu, Finland \\ ${ }^{2}$ Department of Social Research, University of Helsinki, Helsinki, Finland
}

\begin{abstract}
Aims: Paper discusses the impact of the neuroscientific concept of addiction and expectations related to neurosciences in a clinical setting for treatment of addiction disorders.

Design: A case study based on qualitative analysis of scientific publications, research plans, presentations, and interviews of Finnish experts in gambling addictions.

Setting: The case studied is a joint project for experimentation of medication (naltrexone) in treatment of gambling addiction by National Institute of Health and Welfare (THL) and Gambling Clinic, a center specialized in counseling for gambling addicts in Helsinki.

Results: Although Finnish experts think that deep down all addictions share the same neural mechanisms, they consider gambling addiction a complex phenomenon. Clinical experiments seem to have two parallel objectives: neurophysiological malfunctions of the brain and the addict as the person. Two epistemologies and two concepts of addiction are working side by side in the clinical reasoning of the Finnish experts: the neurobiological one for framing the 'addicted brain', and the one derived from cognitive behavioral therapy for the addict.
\end{abstract}

Conclusions: The role of the neurobiological concept of gambling addiction is to back up the therapeutic promise of the experimental project. In a reciprocal manner, the expectation to extend treatment options by the project findings justifies the neuroscientific approach.

Gambling addiction is acknowledged as a significant social problem, and efforts to develop its prevention and treatment have intensified since the end of the twentieth century (Halme \& Tammi, 2008; Shaffer \& Martin, 2011; Tammi, 2008). At the same time, the notion that all sorts of addictions are essentially unitary has gained ground in research, clinical practice, and regulatory policy, and the application of the concept has expanded from substance use to behavioral addictions, gambling addiction included (Campbell, 2007; Vrecko, 2010). Parallel to this expansion, the view that neurosciences will provide the key for understanding of addictions and for development of efficient treatments has been reinforced (e.g., Hyman \& Malenka, 2001; Volkov, Baler, \& Goldstein, 2011). Neuroscientific models of explanation have also been applied in the research and treatment of gambling addiction (Joutsa et al., 2012; Kaasinen, Halme, \& Alho, 2009; Potenza, 2008; Potenza, Sofuoglu, Carroll, \& Rounsaville, 2011), and drugs with direct effects on neurobiology have been used in experimental treatments for over a decade (e.g., Grant, Kim, \& Potenza, 2003). Despite these developments, Blaszczynski and Nower (2002) note, "there is no single conceptual theoretical model of gambling that adequately accounts for the multiple biological, psychological and ecological variables contributing to the development of pathological gambling.”

The implementation of neurosciences in current research and treatment of gambling addiction is not different from the situation in research and treatment of mental and behavioral disorders in general. Despite the progress of research in neurosciences, clinical reasoning and treatment practices are not directed by any model of explanatory synthesis. Instead, many theoretical approaches contribute to the discussion side by side, and the impact of neurosciences is unclear and restricted (Helén, 2011b; Pickersgill, 2010). Nevertheless, great expectations are attached to research of neurobiology of depression, anxiety, and various addictions by scientists, clinicians, policymakers, and lay public. However, it is not clear to what extent research in neurosciences and its applications are able to meet the expectations, since translation and articulation of neurosciences into conceptual landscapes of psychological research, psychiatric treatment, and administrative practices have proven rather complicated (e.g., Hyman, 2007; Kalant, 2010). 
Our paper unfolds the indeterminacy of the 'neuro-turn' in the management of mental and behavioral disorders (Littlefield \& Johnson, 2012; Pickersgill \& van Keulen, 2011; Rose \& Abi-Rached, 2012) through an analysis of a concrete case. We focus on gambling addiction and, more specifically, on a trial in which medication is used experimentally in the treatment of gambling addicts. Our study has two objectives: first, to map out a scientific and professional milieu in which neurosciences are applied in actual treatment and, second, to analyze experts' reasoning by which they translate, adapt, or even resist the models and findings of neurosciences in their practices. The subject of our study is an applied discourse that creates a framework of thought in which gambling as a behavioral addiction becomes conceivable and its treatment gains a reasonable basis in the current clinical and institutional context of addiction treatment (see Helén, 2011a).

\section{Method}

Our case is a joint project of National Institute of Health and Welfare (THL) and Gambling Clinic, a center specializing in counseling for gambling addicts in Helsinki. The protocol of the trial is to experiment with medication in treatment so that the patients will self-administer the drug on demand with the support of cognitive psychotherapy in a standard double-blind arrangement. The project is a follow-up study to a pilot study with 39 research subjects carried out in 2009 (Lahti, Halme, Pankakoski, Sinclair, \& Alho, 2010). The pilot study showed positive results in the treatment outcomes but the effect of medication remained unclear. The current study, launched in spring 2011, is invested with promises of clarifying the potential of medication in the treatment of gambling addiction. The THL research group is closely linked with a research team at Turku PET Centre (University of Turku) studying dopamine metabolism in the brain associated with pathological gambling (e.g., Joutsa et al., 2012).

The component of neurosciences in our case is embodied by naltrexone (molecular formula $\mathrm{C}_{20} \mathrm{H}_{23} \mathrm{NO}_{4}$ ), the drug used experimentally for treatment. Naltrexone is an opioid antagonist developed for the treatment of heroin addiction as a 'non-euphoric' alternative to methadone in the late 1970s. For this purpose, naltrexone proved rather unsuccessful. The drug got a new life in the early 1990s with findings of its efficacy as medication for alcoholism. In 1994, the Food and Drug Administration in the United States approved it for such purpose, and the drug corporation Merck re-patented and rebranded naltrexone as Revia and started to market it as a "smart drug" against alcohol addiction (Vrecko, 2009). In the late 1990s, naltrexone was used in experiments with the treatment of gambling addiction and findings were favorable. Today, naltrexone is often considered an effective and recommendable medication for gambling addiction (Grant et al., 2003; Kim, Grant, Adson, \& Shin, 2001; National Center for Responsible Gambling [NCRG], 2009; Problem Gambling Research and Treatment Center, 2011).
The clinical effects of naltrexone in addiction treatment are seen to be based on its effects in the neurotransmitter metabolism in the brain. The drug works by inhibiting dopamine release in the "reward circuitry" located in the mesolimbic and hypothalamic brain regions. As a result of a neurobiological blockade, the person being treated with naltrexone does not feel drinking alcohol or gambling pleasurable and rewarding (Gonzales \& Weiss, 1998; Lee et al., 2005).

The naltrexone experiment (NT in the following) by THL and Gambling Clinic adopted core ideas and approaches from both international research and domestic sources. In Finland, there is a prominent tradition of studies, since the 1970s, on the physiology of alcoholism using animal models. In fact, Finnish research groups were in the frontline to re-establish opiate antagonists as an effective treatment for alcoholism, and clinical experiments of naltrexone treatment for alcoholism were also carried out in Finland in the 1990s and 2000s (Sinclair, 2001). A leading expert in NT was involved in some of these studies, from which the idea of using the drug on demand is largely derived (e.g., Alho, Heinälä, Kiianmaa, \& Sinclair, 1999). However, the rationale of alcoholism and drug addiction treatment has been (and still is) predominantly embedded in the psychosocial addiction concept and management practices in Finland. Social factors related to excessive drinking and drug abuse have also been greatly emphasized due to a strong tradition of sociological alcohol research. As a consequence, a rather strong underlying tension between biological approaches and psychosocial orientation in treatment is a notable characteristic of the Finnish addiction expertise (e.g., Selin, 2011.)

Our data consists of scientific papers, research plans, and public presentations by the NT experts. In addition, we have interviewed five persons who are conducting experiments or are professionally associated with them. The interviewees are trained in psychology, neurophysiology, and addiction medicine. The interviews were made between spring 2012 and summer 2013, they lasted from 30 minutes to 1 hour and 40 minutes, and they were taped and later transcribed.

We have analyzed printed material and interviews side by side, and our analysis is strictly embedded in and directed by our data as we attempt to capture gambling addiction as it is understood, conceptualized, and reasoned over by the experts involved in research and clinical work. In this sense, we follow the methodological approaches of grounded theory. Our analysis is focused on problematization in practice: we study the ways certain issues are seen as problems and worked out and contexts of reasoning and practice in which the problems emerge, are defined, and are attempted to be solved (Helén, 2005). Three questions direct our study: How do the experts conceive of gambling as a 'disorder' and an 'addiction'? What kind of matrix of interpretation directs the experts when they apply and articulate neuroscientific explanations and findings into clinical addiction concepts embedded in psychology and social sciences? How do the experts 
evaluate the applicability of neurosciences and what sort of expectations do they attach to them?

\section{Results}

\section{Unitary Addiction}

The NT experts share a unitary view of addiction as the premise for their reasoning and work, even though they avow that addictions are complex phenomena and the object of research and treatment is theoretically and conceptually unequivocal (on disunity of addiction, see Blaszczynski \& Nower, 2002; Windle, 2010). For them, "unitary" signifies an idea that different forms of addictive behavior have core features and a mechanism in common, presumably to be found in the neurobiology of the brain. The Finnish experts ordinarily present this view in their published papers and interviews. More precisely, they seem to think that addiction disorders, pathological gambling included, are associated with malfunctions of dopamine metabolism in the brain regions called the reward circuits (Kaasinen, Halme, \& Alho, 2009):

We know that naltrexone and nalmefene are opiate receptor antagonists and there are lots of opiate receptors in the reward area. The way the medication works is that it blocks overstimulation of the reward area [which] is associated with rising dopamine levels and many, many other things. I consider this overstimulation to be the same thing as dependence or that one cannot control something. Whether it is alcohol or gambling. You don't need any substance, you can become addicted to running also. That's the same thing: over-stimulation of the reward area. (H2, Specialist in addiction medicine, interview, 14 June 2012)

Finnish experts' reasoning about the unitary addiction concept has a particular feature. Historically, the concept of addiction has been developed in the context of substance use and with people pathologically addicted to alcohol, opiates, or other hard drugs, and the application of the concept is disseminated from substance use to behavioral addictions like excessive gambling or shopping (Campbell, 2007). Contrary to this, the experts in NT consider pathological gambling a 'pure addiction' because addictive behavior and experience are not attached to any substance or outside affective agent. For this reason, gambling addiction can be seen as a general model of addiction:

PG [pathological gambling] shares many of the same diagnostic criteria as substance use disorders $(. .$.$) the primary difference is that in PG$ no substance is present. Thus research on PG provides us a pure insight into the neurophysiologic features of addictive behavior and may guide the development and testing of effective treatments for other addictions, too. (Lahti et al., 2010, p. 36)

\section{Figure 1}

The main structures and circuits of the reward system in the human brain (Kaasinen, Halme \& Alho, 2009; Korpi, 1999)

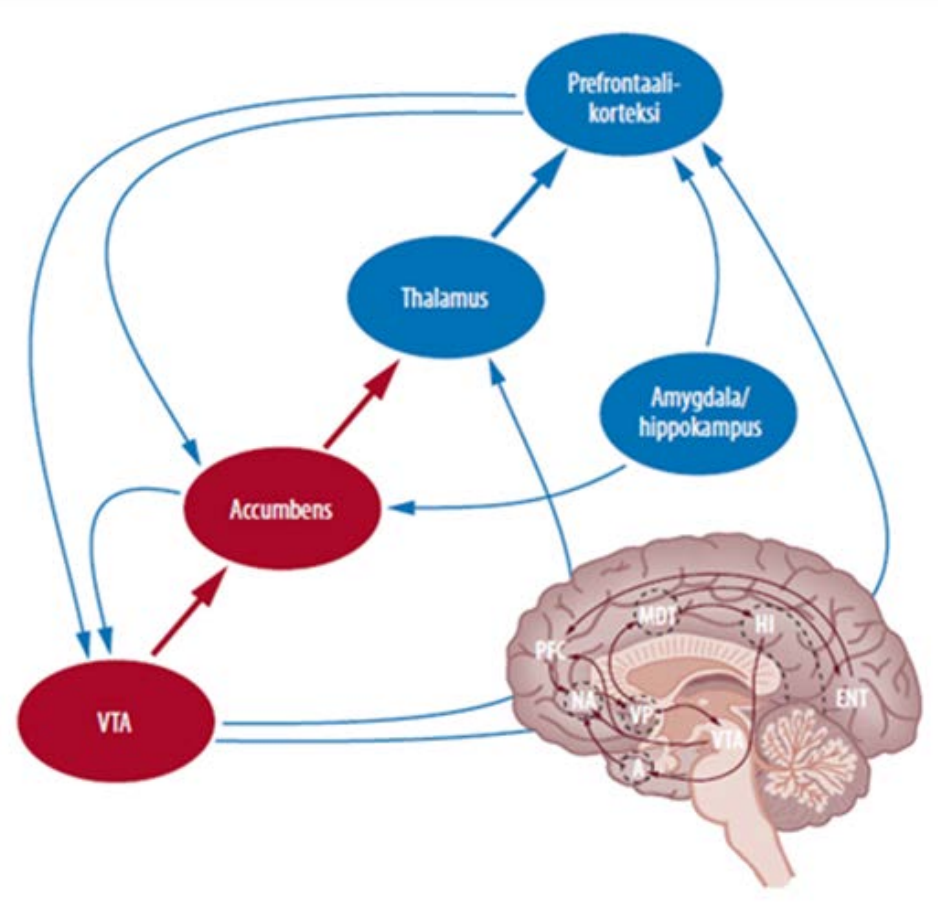


Current neuroscientific approaches tend to align with the conceptualization of mental and behavioral disorders in terms of disposition and susceptibility. This tendency is similar to an increasing emphasis of personal susceptibilities on the molecular level as the target of biomedical research (Rose, 2007). In the Finnish discussion, this idea is usually connected with the view of an inborn, genetic trait that predisposes the person - or, rather, his or her brain - to develop addictive behavior. However, the expert reasoning does not stop at 'susceptibility genes' but continues to an interaction of genetic traits and environment in the onset of gambling addiction, which reflects a general tendency in early twenty-first-century molecular medicine to define pathologies in terms of risk, susceptibility, and geneenvironment interaction (Rose, 2007).

I've got the feeling that the environment affects a lot. There may be an innate disposition towards addiction and it is the exposure to environment that [affects] what you become addicted to. Whether it's alcohol or drugs or sex or whatever. (...) We all are addicted to things and that has been the base of our survival (...) we are dependent on food, we crave it and get attached to things. That's a very human thing. But when does it become a problem? (H1, Expert in neurophysiology, interview, 13 March 2012)

As this quotation indicates, the experts come across the complexity of addiction when they begin to think about the interplay of genetic and environmental factors and the processes by which cerebral mechanisms regulating experiences of reward and excitement become vulnerable to addiction. The Finnish experts readily admit this and even emphasize that gambling addiction is essentially a complex phenomenon. This emphasis is closely related to problematization of treatment. Although the NT experts frame gambling addiction in neurobiological terms and consider that deep down all addictions share the same neural mechanisms, they do not claim that the treatment should be focused solely on the brain.

The exact target is of course the brain (...) the brain and the reward system. But we have to consider that the patient is being treated as a whole and we cannot think that we would treat only the reward system or try to normalize its functions. When it comes to addictions there's always learning involved. These are completely different systems (...). It is such a complex process that we cannot just think that we would treat only one piece of it and that would solve the whole problem. (H2, Specialist in addiction medicine, interview, 14 June 2012)

The NT experts tend to think that neurobiological approach to gambling addiction needs a supplementary approach in the clinical and therapeutic context that would bring the patient into the picture. Consequently, clinical experiments like NT seem to have two parallel objectives: neurophysiological malfunctions of the brain and the addict as the person. Such a duality and the related problems of multifactorial disorders are also characteristic of other fields of current psychiatry (see Helén, 2007; 2011b; Pickersgill, 2010). In NT, the doubling of the object of the experiment points out a significant aspect of the translation of neurosciences in clinical practice. Namely, the experts' orientation toward the neurobiological concept of gambling addiction is derived from their interest in managing and curing pathological gambling and embedded in the idea of the treatability of the disorder (see Helén, 2011a).

\section{Prospects for Treatment}

So far, cognitive behavioral therapy has been the most recommendable and 'evidence-based' treatment for gambling addiction, according to the international expert opinion (Lahti, Castrén, Tenhola, Heinälä, Alho, 2012: 415; NCRG, 2009; Petry et al., 2006). With the increase in research on the cerebral mechanisms of pathological gambling, new options for treatment have become reasonable. Thus, the neurobiological view of the Finnish experts is framed by an expectation: the unfolding of the neurophysiological mechanism of the risk and onset of gambling addiction through neurosciences will lead to new treatments targeted at specific disordered brain functions (Lahti, 2011; Lahti et al., 2012). Since opiate antagonists have shown the most promising therapeutic effect in clinical trials (Grant et al., 2006; Kim et al., 2001; Lahti et al., 2012), naltrexone has a key role in the epistemic and practical choreography of NT; on the one hand, the promise of neuroscientific approach is embodied by the drug, and, on the other hand, it is a means to demonstrate effectiveness of a new cure.

Finnish experts see clearly that translation of the neurobiological approach in the treatment setting is complicated, largely due to the fact that multiple factors besides brain functions contribute to the onset of and recovery from gambling addiction in the patient as a whole. For this reason, the experts do not expect medication to be a miracle cure:

[Naltrexone] has been used for decades in treatment of alcoholism for example, so it is nothing new. It was developed for treatment of alcoholism and has been also used with treatment of opiate-addiction (...). The idea is that addiction as a phenomenon takes place in the same regions in the brain; there are the same problems with neurotransmitters. (...). It would seem to be the most promising method of treatment. But when we are dealing with behavioral addictions there are always other methods that have to come first (...) the patient's own motivation is always the key to change. The medication can support the change in the beginning of the process when the urge to gamble is too powerful. (H1, Expert in neurophysiology, interview, 13 March 2012)

The neurobiological concept of addiction is pivotal for the reasoning of the NT experts because it justifies and provides scientific basis for an extension of treatment 
options of gambling addiction to the pharmaceutical field. Nevertheless, the object of addiction treatment is considered to be dual; therefore a specific role is defined for medication of the brain alongside the management of the patient. The NT project experiments with a combination of cognitive behavioral therapy and medication, which is seen to be the most effective way of treating gambling addiction. According to the experts, medication may make room for a psychotherapeutic intervention and recovery. While naltrexone halts the craving to gamble, therapy becomes possible.

This [study] should give new information of what is helpful. If we can indeed stop the urge to gamble with this opiate antagonist and maybe then work out these things in therapy (...). I think this is a great idea, this combination. (H3, Clinical psychologist, interview, 18 July 2012)

In the expert discourse, the role of neurobiological concept of addiction is not just providing support for pharmaceutical treatment. The NT project is also expected to produce results useful for the development of evidencebased guidelines for the treatment of gambling addictions in Finland. Regarding these objectives, neuroscientific reasoning and naltrexon are seen to provide the focus for attempts to gain a deeper understanding of the problem and clarify treatment procedures.

The goal is to find an effective way of treating gambling addiction [and] to have recommendations for treatment in Finland and a clear protocol for the service system. (...). It is almost like the Wild West at the moment, and the kind of treatment you get depends very much on who you see and where you are. (H1, Expert in neurophysiology, interview, 13 March 2012)

\section{Discussion}

Experiments like NT are essentially promissory, and the role of the neurobiological concept of gambling addiction is to back up the therapeutic promise (see Pickersgill, 2011; Rubin, 2008) of the project. In a reciprocal manner, the expectation to extend treatment options justifies the neuroscientific approach. The therapeutic promise of NT is twofold: on the one hand, the project aims to demonstrate and specify the suitability of naltrexone for treatment of pathological gambling, and on the other hand, experiment with medication is meant to provide evidence for developing the gold standard for treatment.

Yet experts consider gambling addiction a profoundly complex phenomenon. For this reason, their view of the impact of neurosciences in the practical context is ambivalent, and they do not expect naltrexone or any other medication to become a magic bullet for gambling addiction. Furthermore, two epistemologies - and two concepts of addiction - seem to work side by side in the clinical reasoning of the Finnish experts: the neurobiological in which the addicted brain is framed, and the cognitive behavioral for the addict as the person.

The experts in NT do not think that medication alone is a sufficient cure for gambling addiction and consider it a help for cognitive behavioral therapeutic intervention. Thus, a psychotherapeutic model for addiction treatment seems to play a major part in the standard NT is expected to develop. In discussions of bringing pathological gambling 'under control with right procedures' the experts emphasize the importance of the patients' own motivation and action to control the problem, as related to the pharmaceutical treatment. Gambling addiction is often compared to diabetes as a chronic illness that can be kept under control with a joint effort of the patient and a medical expert. For the past 25 years, diabetes has been a favorite somatic disease to which common mental disorders, depression in particular, have been compared in professional and lay discourse (Helén, 2011a). The comparison to a chronic disease shows gambling addiction in a new light. When gambling addiction treatment - or its future - is defined within the diabetes regime, the person under treatment is not anymore considered the addict who lives at the mercy of irresistible inner urges. Instead, he or she is seen as the patient capable of monitoring and controlling personal action with means of self-management, medication included. This change implies detachment of addiction from the person, since the idea of addiction as 'a disease of the will' signifying the self of the addicted person (see Valverde, 1998) is no longer the presupposition of treatment. When gambling addiction is seen alike to a treatable chronic condition, it is conceived of as a susceptibility, or a risk, to crave and behave in an excessive manner that can be constantly monitored and handled by the gambler him- or herself, with a little help from an expert counselor and medication - in a similar way as the diabetic maintains his or her blood sugar level normal by self-administering insulin injections and keeping up his or her prescribed diet. Such a treatment rationale tends to emphasize the ability of mastering personal craving and conduct by the patients themselves; thus it may distance addiction treatment far afield from psychotherapeutic approaches.

\section{References}

Alho, H., Heinälä, P., Kiianmaa, K., \& Sinclair, J. (1999). Naltrexone for alcohol dependence: Double-blind placebo-controlled Finnish trial. Alcoholism: Clinical and Experimental Research, 23(s5), 46A.

Blaszczynski, A., \& Nower, L. (2002). A pathways model for problem and pathological gambling. Addiction, 97, 487-499.

Campbell, N. (2007). Discovering addiction. Ann Arbor, MI, United States: University of Michigan Press.

Gonzales, R. R., \& Weiss, F. (1998). Supression of ethanolreinforced behavior by naltrexone is associated with attenuation of the ethanol-induced increase in dialysate dopamine levels in nucleus accumbens. Journal of Neuroscience, 18, 10663-10671. 
Grant, J. E., Kim, S. W., \& Potenza, M. N. (2003). Advances in the pharmacological treatment in pathological gambling. Journal of Gambling Studies, 19, 85-109.

Grant, J. E., Potenza, M. N., Hollander, E., CunninghamWilliams, R., Nurminen, T., Smits, G., \& Kallio, A. (2006). Multicenter investigation of the opioid antagonist nalmefene in the treatment of pathological gambling. American Journal of Psychiatry, 163, 303312.

Halme, J. T., \& Tammi, T. (2008). Katsaus ongelmapelaamisen ja patologisen pelaamisen hoitoa koskevaan vaikuttavuustutkimukseen: Tutkimus on vähäistä ja tulokset epävarmoja [An overview of studies on the treatment of gambling problems and pathological gambling]. Sosiaalilääketieteellinen aikakauslehti, 45, 301-313.

Helén, I. (2005). Genealogia kritiikkinä [Genealogy as critique]. Sosiologia, 42, 93-109.

Helén, I. (2007). Multiple depression: Making mood manageable. Journal of Medical Humanities, 28, 149172.

Helén, I. (2011a). The depression paradigm and beyond: The practical ontology of mood disorders. Science Studies, 24, 81-112.

Helén, I. (2011b). Is depression a brain disorder? Neuroscience in mental health care. In M. Pickersgill \& I. van Keulen (Eds.), Sociological reflections on neuroscience (pp. 123-152). Bingley, England: Emerald.

Hyman, S. E. (2007). Can neuroscience be integrated into the DSM-V? Nature Reviews Neuroscience, 8, 725732.

Hyman, S. E., \& Malenka, R. C. (2001). Addiction and the brain: The neurobiology of compulsion and its persistence. Nature Reviews Neuroscience, 2, 695703.

Joutsa, J., Johansson, J., Niemelä, S., Ollikainen, A., Hirvonen, M. M., Piepponen, P., ... Kaasinen, V. (2012). Mesolimbic dopamine release is linked to symptom severity in pathological gambling. NeuroImage, 60, 1992-1999.

Kaasinen, V., Halme, J., \& Alho, H. (2009). Pelihimon neurobiologiaa [On neurobiology of craving for gambling. Duodecim, 125, 2075-2083.

Kalant, H. (2010). What neurobiology cannot tell us about addiction. Addiction, 105, 780-789.

Kim, S. W., Grant, J. E., Adson, D. E., \& Shin, Y. C. (2001). Double-blind naltrexone and placebo comparison study in the treatment of pathological gambling. Biological Psychiatry, 49, 914-921.

Korpi, E. (1999). Huumeriippuvuuden patofysiologia [The pathophysiology of drug dependency]. Suomen Lääkärilehti, 54, 3687-3693.

Lee, Y. K., Park, S. W., Kim, Y. K., Kim, D. J., Jeong, J., Myrick, H., \& Kim, Y. H. (2005). Effects of naltrexone on the ethanol-induced changes in the rat central dopamine system. Alcohol and Alcoholism, 40, 297-301.

Lahti, T. (2011). Peliriippuvaisilla on havaittu muutoksia useiden eri hermovälittäjäainejärjestelmien toiminnassa [Changes have been observed in pathological gamblers of various neurotransmitter systems in operation]. Erikoislääkäri, 21(1), 15-17.

Lahti, T., Castren, S., Tenhola, H., Heinälä, P., \& Alho, H. (2012). Rahapeliriippuvuutta voidaan hoitaa [Gambling addiction can be treated]. Suomen lääkärilehti, 67, 413-416.

Lahti, T., Halme, J., Pankakoski, M., Sinclair, D., \& Alho, H. (2010). Treatment of pathological gambling with naltrexone pharmacotherapy and brief intervention: A pilot study. Psychopharmacology Bulletin, 43, 35-44.

Littlefield, M., \& Johnson, J. (2012). The neuroscientific turn. Ann Arbor, MI, United States: University of Michigan Press.

National Center for Responsible Gambling (NCRG). (2009). Roads to recovery from gambling addiction. Boston, MA, United States: National Center for Responsible Gambling.

Petry, N. M., Ammerman, Y., Bohl, J., Doersch, A., Gay, H., Kadden, R., ... Steinberg, K. (2006). Cognitivebehavioral therapy for pathological gamblers. Journal of Consulting and Clinical Psychology, 74, 555-567.

Pickersgill, M. (2010). From psyche to soma? Changing accounts of antisocial personality disorders in the American Journal of Psychiatry. History of Psychiatry, 21, 294-311.

Pickersgill, M. (2011). 'Promising' therapies: Neuroscience, clinical practice, and the treatment of psychopathy. Sociology of Health \& Illness, 33, 448464.

Pickersgill, M., \& van Keulen, I. (Eds.). (2011). Sociological reflections on neuroscience. Bingley, England: Emerald.

Potenza, M. N. (2008). The neurobiology of pathological gambling and drug addiction: An overview and new findings. Philosophical Transactions of the Royal Society B: Biological Sciences, 363, 3181-3189.

Potenza, M. N., Sofuoglu, M., Carroll, K. M., \& Rounsaville, B. J. (2011). Neuroscience of behavioral and pharmacological treatments for addictions. Neuron, 69, 695-712.

Problem Gambling Research and Treatment Center. (2011). Guideline for screening, assessment and treatment in problem gambling. Victoria, Australia: Monash University.

Rose, N. (2007). The politics of life itself. Princeton, NJ, United States \& Oxford, England: Princeton University Press.

Rose, N., \& Abi-Rached, J. (2012). Neuro. Princeton, NJ, United States \& Oxford, England: Princeton University Press.

Rubin, B. (2008). Therapeutic promise in the discourse of human embryonic stem cell research. Science as Culture, 18, 13-27.

Shaffer, H. J., \& Martin, R. (2011). Disordered gambling: Etiology, trajectory, and clinical considerations. Annual Review of Clinical Psychology, 7, 483-510.

Selin, J. (2011). Huumeriippuvuuden hoito ja lääketieteen haaste. Terapeuttinen järkeily ja hallinta psykososiaalisissa huumehoidoissa 1965-2005 [Drug dependence treatment and medical challenge. Therapeutic reasoning and management of 
psychosocial drug treatment 1965-2005]. Sosiologia, 48, 117-133.

Sinclair, J. (2001). Evidence about the use of naltrexone and for different ways of using it in the treatment of alcoholism. Alcohol and Alcoholism, 36, 2-10.

Valverde, M. (1998). Diseases of the will. Cambridge, England: Cambridge University Press.

Volkov, N., Baler, R., \& Goldstein, R. (2011). Addiction: Pulling at the neural threads of social behaviors. Neuron, 69, 599-602.

Vrecko, S. (2009). Therapeutic justice in drug courts: Crime, punishment and societies of control. Science as Culture, 18, 217-232.

Vrecko, S. (2010). Birth of a brain disease: Science, the state and addiction neuropolitics. History of the Human Sciences, 23(4), 52-67.

Windle, M. (2010). A multilevel developmental contextual approach to substance use and addiction. BioSocieties, 5, 124-136. 